\title{
The Experimental Study of Nodular Cast Iron Volume Changes during Solidification
}

\author{
Abel Tadesse ${ }^{1, a^{*}}$, Hasse Fredriksson ${ }^{1, b}$ \\ ${ }^{1}$ Royal Institute of Technology, Brinellvägen 23, Stockholm, SE-100 44, Sweden \\ aattad@kth.se, bhassef@kth.se
}

Keywords: Volume changes, Solidification, NCI, LVDT, Hypo- and Hyper-eutectic, Nodule count.

\begin{abstract}
The volume changes during solidification of Nodular Cast Iron (NCI) in the sand mold studied using Linear Variable Differential Transformer (LVDT). Both hypo- and hyper-eutectic compositions are considered by adjusting the carbon fraction in the composition during the experimental studies. The microstructural analysis and measurements are taken from the samples to evaluate the different phases present, the nodule count and size distributions. At the beginning of solidification, the experimental result shows the volume change is negligible. During the eutectic growth, the samples expand until the end of solidification. The displacement measurement shows the expansion continued when solidification finished. The volume change studies during solidification indicate that as the carbon fraction increases the volume expansion decreases. On the other hand, it is found that the pore fraction decreases as the volume expansion decreases. The fraction of primary austenite decreases as the fraction of carbon increases, and that leads to having a lower pore fraction.
\end{abstract}

\section{Introduction}

As a result of high mechanical properties like ductility and machinability [1], NCI is one of the widely-used cast iron types in the automotive industries. The relatively lower cost of production of heavy section parts is also the other reason for selecting them over the other [2]. Several factors can influence the property of the NCI during solidification. Among them, the alloying element, cooling rate, and microsegregation are the reasons that affect most. The presence of different elements in the molten metal can promote or restrict the growth of nodule graphite and homogenize the structure [3]. At the same time, varying cooling rate will also influence the microsegregation of elements, such as carbon, during solidification [4]. The variations in nodularity, nodule size and distribution will then alter the volume changes of the casting during solidification. These eventually lead the casting to have variable displacement changes along the different sides of the casting and becomes a factor for microporosity formation.

Up-to-date, not many researches are conducted in the areas of the volume changes during solidification of cast iron. During the early time, [5-7] performed a study on the volume changes during solidification of NCI and lamellar graphite (LG) with the same carbon equivalents and observed higher shrinkage on the former than the later one in the primary austenite solidification region. At the same time, the LG display lesser expansion in the eutectic solidification region than $\mathrm{NCI}$. Elements such as $\mathrm{Si}, \mathrm{Ce}, \mathrm{Sb}$, and $\mathrm{Sn}$ can promote or restrict the formation of chunky graphite over nodule graphite in the structure [8-9]. As a result, different micro shrinkage observed in their samples. In addition to that, different approaches have been followed by [10-14] to measure the displacement changes during solidification. The study conducted by [15] also suggests the molding media can influence the expansion during solidification.

Considering its broader application in the industries and susceptibility to pore formation during casting, a better understanding of the principles and factors affecting the volume changes could help one to control the micro defects. In this research, multi-directional displacement changes with a cooling curve is simultaneously measured during solidification of different alloys. Later, the displacement measurements are used to describe the various phase regions in the cooling curve and the relation with the microstructural differences and micro shrinkages. 


\section{Experimental Procedures}

In the first batch, three types of alloys with only differences in carbon content are used in the LVDT experiments. The second batch of the alloys represents an industrial trial in the foundry. All the displacement experiments are conducted in dry sand mold. Similar method and setup adopted from the earlier LG studies to perform the LVDT experiments [16]. During the inoculation process in the first three alloys, the same amount of Reseed $^{\circledR}$ and Ferro-manga-silicon is used.

Mold making and sensors placement. The sand mold is made by mixing silica sand and Sodium Silicate [17-18]. Then a refractory coating paint is applied to the mold cavity and kept inside a heating furnace for curing. The mold cavity is roughly $5 \times 7 \times 1 \mathrm{~cm}$ after curing. In each trial, four LVDT sensors were employed on four sides of the thin plate except the top and bottom parts due to space limitation. The sensor tips are coupled with the molten NCI with the help of quartz rods. During the experiments, quartz tubes were inserted inside the sand mold to promote a smooth movement of the quartz rods. The cooling curves in each experiment were measured from the center of the casting by using S-type thermocouple placed from the top surface. The LVDT sensors have an accuracy of \pm 0.1 percent of the measurement, and the thermocouple has an accuracy of $\pm 3{ }^{\circ} \mathrm{C}$ in higher temperature region. The components and arrangement of the LVDT experimental setup is shown in Fig. 1.

Table 1: The chemical compositions of alloys in Wt. Pct.

\begin{tabular}{|c|c|c|c|c|c|c|c|c|c|}
\hline \multirow{2}{*}{ Alloy } & \multirow{2}{*}{$\mathrm{C}$} & \multirow{2}{*}{$\mathrm{Si}$} & \multirow{2}{*}{ Mo } & \multirow{2}{*}{$\mathrm{P}$} & \multirow{2}{*}{$\mathrm{S}$} & \multirow{2}{*}{$\mathrm{Mg}$} & \multirow{2}{*}{$\mathrm{Mn}$} & \multicolumn{2}{|c|}{ Inoculant $(\%)$} \\
\hline & & & & & & & & Reseed $^{(\mathbb{R})}$ & $\mathrm{Fe}-\mathrm{Mg}-\mathrm{Si}$ \\
\hline A1 & 3.3 & 1.2 & 0.9 & - & - & - & - & 1 & 2 \\
\hline $\mathrm{A} 2$ & 3.5 & 1.2 & 0.9 & - & - & - & - & 1 & 2 \\
\hline A3 & 3.8 & 1.2 & 0.9 & - & - & - & - & 1 & 2 \\
\hline AF4 & 3.82 & 2.04 & - & 0.02 & 0.01 & 0.07 & 0.14 & - & - \\
\hline AF5 & 3.79 & 2.02 & - & 0.02 & 0.01 & 0.07 & 0.2 & - & - \\
\hline AF6 & 3.87 & 2.05 & - & 0.02 & 0.01 & 0.06 & 0.2 & - & - \\
\hline
\end{tabular}

Melting and Inoculation. The first three alloys are made in a vacuum furnace by using high purity elements (Table 1). Each of these alloys were cut into three pieces, and the middle part is utilized in the LVDT experimentation. The same amount of $\operatorname{Resed~}^{\circledR}(72 \% \mathrm{Si}-1 \% \mathrm{Ca}-1.5 \% \mathrm{Ce}-$ $1 \% \mathrm{Al}$ ) and $48 \% \mathrm{Fe}-5 \% \mathrm{Mg}-47 \% \mathrm{Si}$ inoculants was used in each sample. In the first three samples, the molten metal prepared inside an induction furnace under an inert atmosphere to protect the melt from excessive oxidation. Then, Reseed ${ }^{\circledR}$ and Ferro-manga-silicon were added inside the mold cavity before pouring. 


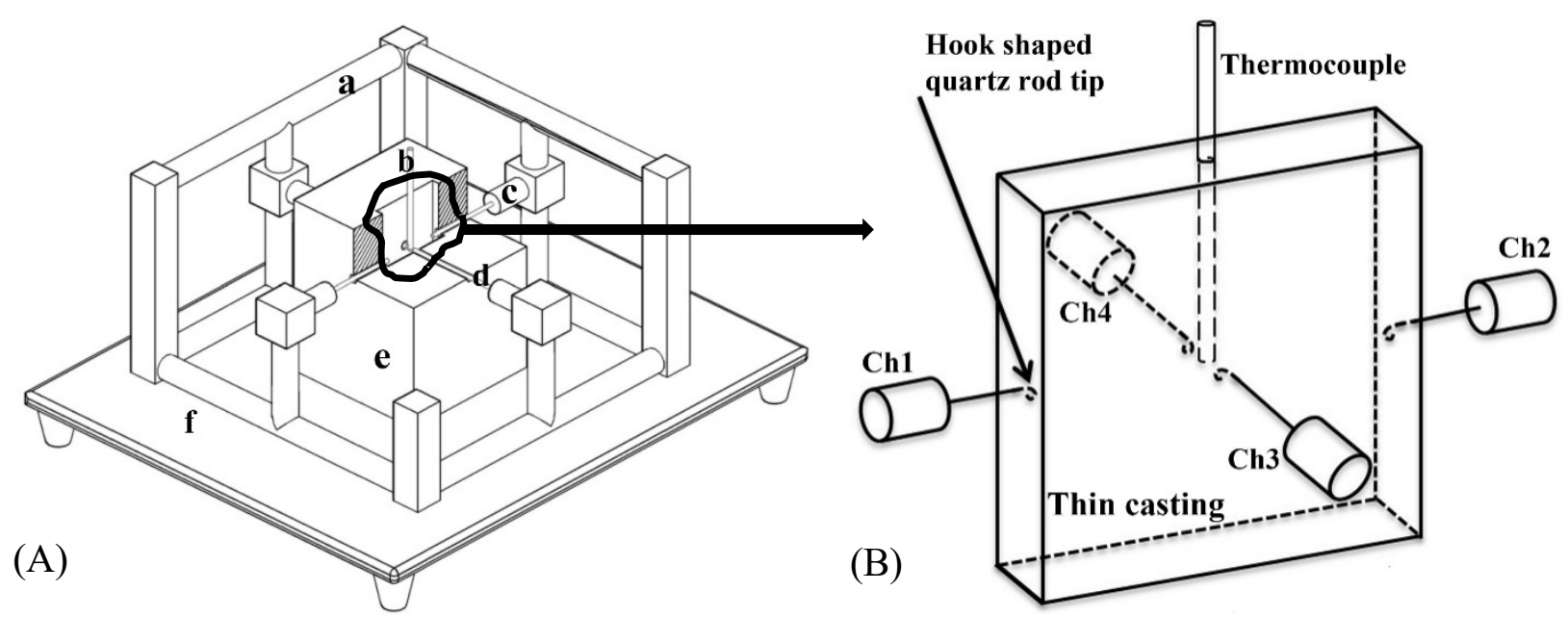

Fig. 1: (A) The LVDT measurement setup that includes a- Metallic frame, b- Thermocouple, cLVDT sensor, d- Quartz rod, e- Sand mold, f- Baseplate. (B) The arrangement of thermocouple \& LVDT sensors. Ch 1-2 and Ch 3-4 measures longitudinal and transversal displacement, respectively.

Metallographic study. Small samples were taken from the middle part of the LVDT experimental casts, mounted in a bakelite, ground with different grades of sandpaper, polished with 3 and $1.5 \mu \mathrm{m}$ diamond suspension liquids. Followed by etching with $2 \%$ nital solution to evaluate the various phase fractions, nodule counts, size distributions and pore fractions under the optical microscope. The analyzed sampling area was roughly $0.118 \mathrm{~cm}^{2}$ for each alloy and eight $100 \mathrm{X}$ microstructures taken from each sample to estimate the nodule count and distribution.

\section{Result}

Unlike the LG [16], the displacement measurements for NCI are different. In all the experiments, the casting shows expansion in the longitudinal direction during solidification. However, the degree of expansion varies from experiment to experiment (shown in Fig. 2). The transversal displacement measurement shows no expansion in all but AF5 as shown in Fig. 2e. During the early solidification in all experiments, the samples show small or no contraction until it reaches the eutectic solidification. Then after, most of the expansion occurs in the eutectic solidification region due to the growth of nodule graphite. After solidification was completed, the samples show contraction until it reached the eutectoid transformation region. In this region, the alloys show expansion, then followed by gradual displacement changes. Depending on the degree of eutectoid transformation [19], samples show higher or lower expansion in this region.

The cooling curves from the first three serials show that on increasing the carbon content, the primary austenite formation region gets decreased. On the other hand, the cast alloys which were made in the foundry show a eutectic solidification. Comparatively, in the first three alloys the eutectic solidification region is shorter compared to the castings made in the foundry. 


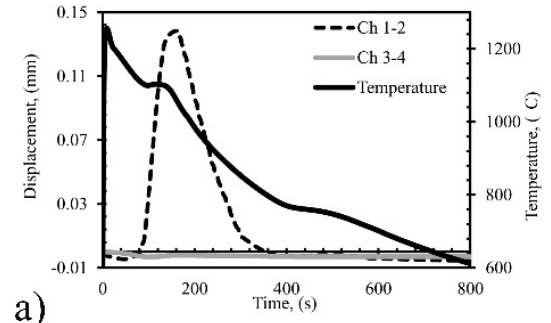

a)

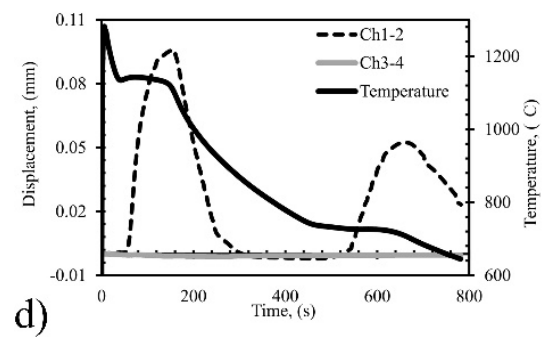

b)
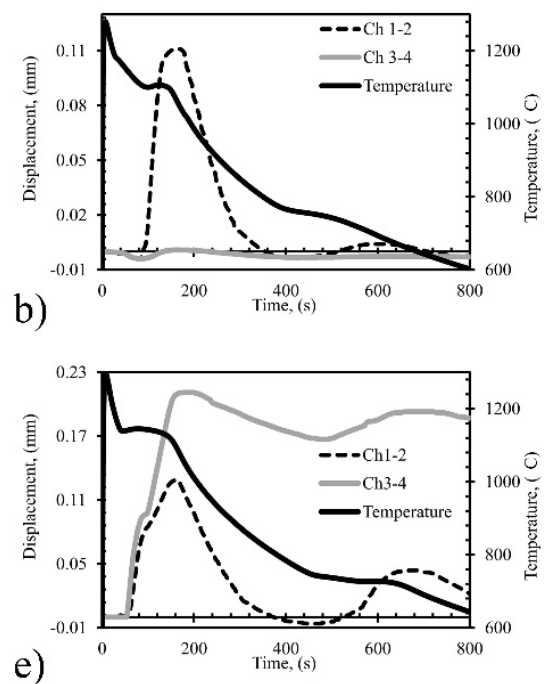

c)
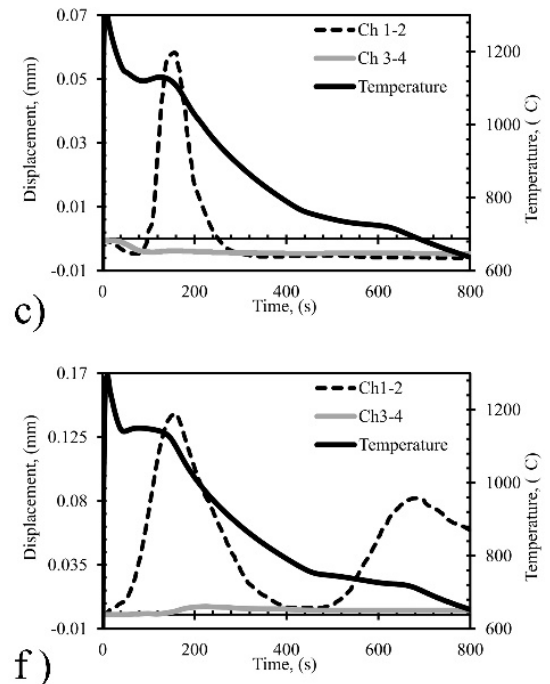

Fig. 2: (a-c) the displacement measurement in the longitudinal and transversal directions with the cooling curves for alloys A1-3, respectively. (d-f) the measurement for alloys AF4-6, respectively.

The microstructural results reveal a difference in nodule size and distributions between the different alloys (Fig. 3). As the amount of carbon increases in the first three alloys, the size of the nodule and the distribution was influenced directly, given that the cooling rates and the amount of inoculant used are the same (Fig. 3a-c). The industrial NCI also shows variation in nodule size and distribution between the samples. At the same time, the amount of ferrite and perlite in each sample looks different. The nodularity of graphite is also different if a comparison is made between the cast samples from the lab and the ones from the foundry. The former samples show less nodularity compared to the later ones.

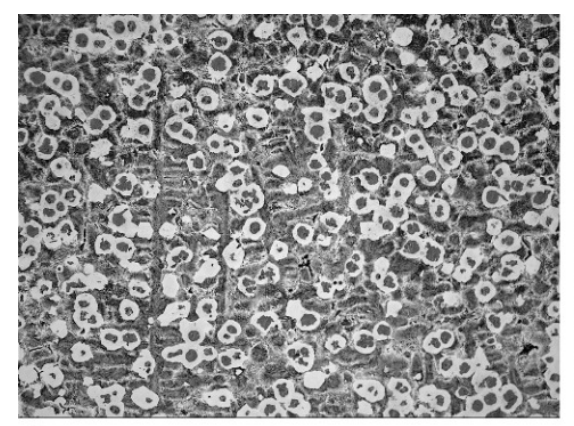

a)

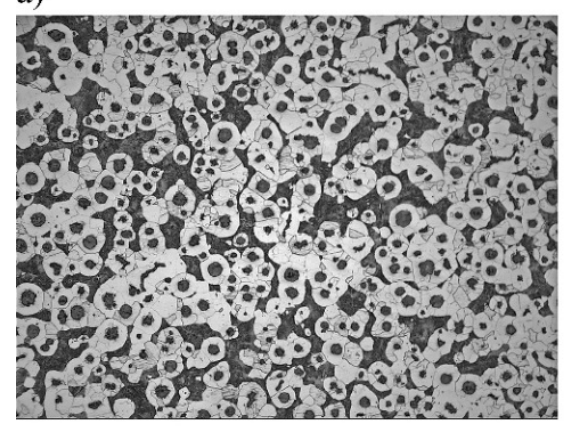

d)

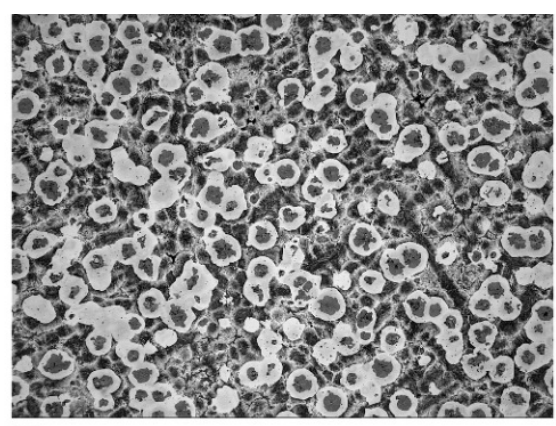

b)

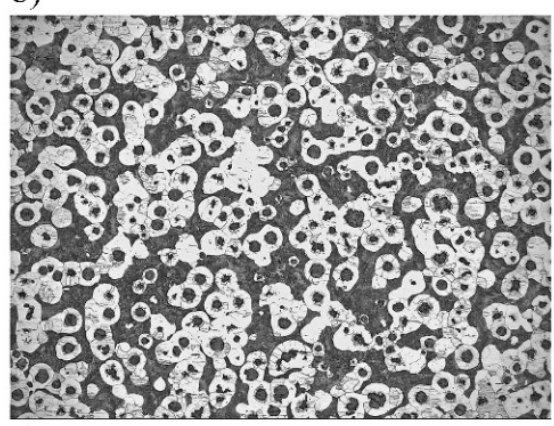

e)

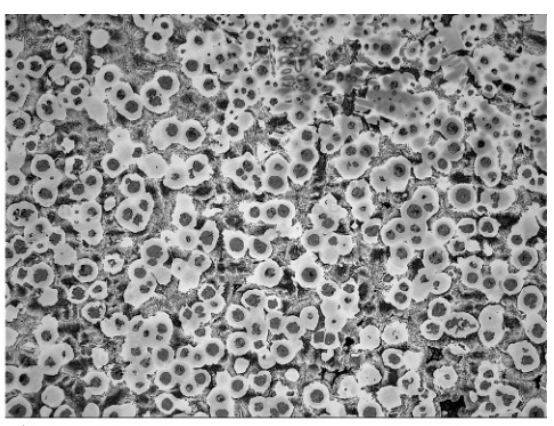

c)

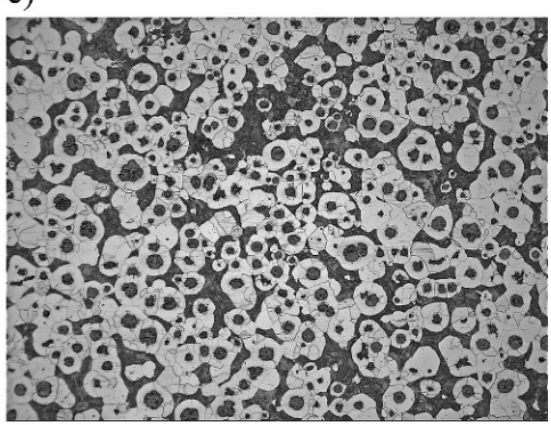

f)

Fig. 3: (a-c) Microstructural changes with increasing carbon content in the first three alloys. (d-f) Cast samples from the foundry. The magnification in all samples is $100 \mathrm{X}$.

The statistical analysis results (Table 2) also show that there is a variation in the pore, nodule count, nodularity, ferrite and perlite fractions of the different samples. As the carbon percentage increases in the first three alloys, an increase in the graphite nodules and ferrite fractions is detected. On the contrary, the perlite and pore fraction decreases with increases in carbon containment. 
Table 2: The average nodule count, nodularity, fractions of pore and different phases from analyzed samples.

\begin{tabular}{ccccccc}
\hline \multirow{2}{*}{ Alloy } & \multirow{2}{*}{$\begin{array}{c}\text { Nodule } \\
\text { count } / \mathrm{mm}^{3}\end{array}$} & \multirow{2}{*}{$\begin{array}{c}\text { Nodularity } \\
(\%)\end{array}$} & Ferrite & Perlite & Graphite & Pore \\
\hline A1 & 171 & 59 & 0.227 & 0.69 & 0.065 & 0.018 \\
\hline A2 & 114 & 62 & 0.244 & 0.668 & 0.072 & 0.016 \\
\hline A3 & 182 & 64 & 0.314 & 0.593 & 0.081 & 0.012 \\
\hline AF4 & 201 & 71 & 0.687 & 0.224 & 0.089 & $<0.01$ \\
\hline AF5 & 143 & 62 & 0.544 & 0.391 & 0.065 & $<0.01$ \\
\hline AF6 & 205 & 73 & 0.664 & 0.229 & 0.107 & $<0.01$ \\
\hline
\end{tabular}

\section{Discussion}

The cooling curve with the LVDT measurements will provide the complete image of how a casting behaves during solidification and further cooling in solidus region. As mentioned earlier, the displacement measurement is only detected in the longitudinal direction except for AF5. The reason for the unidirectional displacement is the higher shrinkage pores formation in the middle section of the casting. The higher shrinkage pores formation in the middle section is related to the growth morphology of the nodule graphite and austenite precipitation. In ductile iron, the growth of the eutectic cells contains nodule graphite surrounded by an austenite layer. These phenomena will lower the graphite content in the last solidifying melt. As a result, shrinkage will be higher in the middle part.

When the casting has higher expansion during solidification, then the remaining molten metal in the last solidified region should have enough graphite to compensate the iron shrinkage. Otherwise, the casting can be prone to micro and macroporosities. An increase in carbon fraction in the composition has a positive effect on nodule graphite fraction and decrease in porosity. It is also observed that the increase in carbon content decreases the austenite formation region. As a result, less austenite will precipitate in the early stage, and more carbon will be present in the remaining liquid that later forms rather higher nodule count and graphite fraction. The increase in nodule count and graphite fraction will eventually lower the micro shrinkage formation during solidification.

When comparison is made between expansion during solidification with its corresponding cooling curve, it shows a deviation from each other. According to the displacement measurement, expansion continues to some extent but solidification is completed earlier when referred with the cooling curve. This further expansion might open-up the solid network, and it can lead to pore formation in the last solidifying region.

The nodule count, nodularity, and fraction of different phases can be altered by changing the chemical compositions and cooling rates. As a result of efficient and controlled melt treatment in the foundry casts, the samples have a higher nodule count, nodularity, and graphite fractions. Consequently, the pore fraction is slightly lower. According to the result, within the range of investigated alloy compositions, if the carbon content in the alloy is close to eutectic or slightly in the hypereutectic region then pore fraction is less. This will underline that if the carbon content during solidification in the remaining liquid is slightly higher, then graphite precipitation in a later stage will compensate the micro shrinkage.

As it is mentioned earlier, depending on the degree of eutectoid transformation [19], samples show higher or lower expansion in this region. The variation in eutectoid transformation has no effect on the micro shrinkage formation, but it may influence the thermal stress development in the casting. Eventually, the casting might be prone to crack formation. However, this observation needs further studies to verify whether it has an influence or not. 


\section{Conclusion}

The study of the volume changes during NCI solidification by simultaneously using the displacement change and cooling curve measurements will provide a complete history of the process. In all experimental trials, the expansion occurs in the eutectic solidification region because of the nodule graphite growth. As the carbon content in the composition increases, the primary austenite formation region gets shorter. The smaller the austenite formation region, the lower the primary austenite and the higher carbon content in the remaining liquid metal. The increase in the carbon content in the molten metal will eventually increase the nodule graphite precipitation in the last solidifying region and decreases the micro shrinkage. Unlike LG, NCI shows higher shrinkage in the middle section of the casting due to the growth morphology of graphite-austenite shell and the higher micro shrinkage.

\section{References}

[1] ISO/TR 10809-1:2009, Cast irons -- Part 1: Materials and properties for design.

[2] G. Erjun, S. Liang, W. Liping, Effect of Ce-Mg-Si \& Y-Mg-Si Nodularizers on the Microstructures \& Mechanical Properties of Heavy Section Ductile Iron, J. of Rare earths. 32(2014) 738-744.

[3] T. Skaland, Ø. Grong, T. Grong, A Model for the Graphite Formation in Ductile Cast Iron: Part I. Inoculation Mechanisms, Metall Trans A. 24(1993) 2321-2345.

[4] G. Rivera, R. Boeri, J. Sikora, Influence of the inoculation process, the chemical composition and the cooling rate, on solidification macro and microstructure of ductile iron, Int $\mathrm{J}$ Cast Met Res. 16(2003) 23-28.

[5] C. Bates, G. Oliver, R. McSwain, Volumetric Changes During Freezing of Ductile Cast Iron, AFS Transactions. 77-59(1977) 289-298.

[6] C. Bates, B. Patterson, Volumetric Changes Occurring During the Freezing of Hypereutectic Ductile Irons, AFS Transactions. 79-64(1979) 323-334.

[7] R. Hummer, A study of the shrinkage and dilatation during solidification of nodular cast iron its relation to the morphology of crystallisation, in: H. Fredriksson, M. Hillert (Eds.), The physical metallurgy of cast iron, MRS Symposia Proceedings, Vanderbilt Avenue (NY), Elsevier, 1984, Vol. 34, pp. 213-222.

[8] H. Nakae, M. Fukami, T. Kitazawa, Y. Zou, Influence of Si, Ce, Sb and Sn on chunky graphite formation, Chin Foundry. 8(2010) 96-100.

[9] H. Nakae, S. Jung, H. Shin, Formation mechanism of chunky graphite and its preventive measures, J Mater Sci Tec. 24(2008) 289-295.

[10] G. Alonso, D. Stefanescu, R. Suarez, et al., Understanding graphite expansion during the eutectic solidification of cast iron through combined Linear Displacement and Thermal Analysis, Int Foundry Res. 66(2014) 2-12.

[11] G. Alonso, D. Stefanescu, R. Suarez, et al., Kinetics of graphite expansion during eutectic solidification of cast iron, Int J Cast Met Res. 27(2014) 87-100.

[12] P. Svidró, A. Diószegi, On problems of volume change measurements in lamellar cast iron, Int J Cast Met Res. 27(2013) 26-37.

[13] I. Svensson, A. Diószegi, On Modelling of Volume Related Defect Formation in Cast Irons, in: P. Sahm, P. Hansen, J. Conley (Eds.), Proceedings of the Ninth International Conference on Modeling of Casting, Welding and Advanced Solidification Processes, Aachen (DE), Shaker, 2000, pp. 102-109.

[14] H. Fredriksson, I. Svensson, Computer Simulation of the Structure Formed During Solidification of Cast Iron, in: H. Fredriksson, M. Hillert (Eds.), The physical metallurgy of cast iron, MRS Symposia Proceedings, Vanderbilt Avenue (NY), Elsevier, 1984, Vol. 34, pp. 237-284. 
[15] M. Chisamera, I. Riposan, S. Stan, et al., Shrinkage evaluation in ductile iron as influenced by mold media and inoculant type, Int J Cast Met Res. 24(2011) 28-36.

[16] A. Tadesse, H. Fredriksson, Volume change during solidification of grey cast iron: its relation with the microstructural variation, comparison between experimental and theoretical analysis, Int J Cast Met Res. 30(2017) 159-170.

[17] J. Brown, Foseco non-ferrous foundryman's handbook, Oxford, Butterworth-Heinemann, 1999, pp. 204-215.

[18] K. Granat, D. Nowak, et al., The influence of microwave heating and water glass kind on the properties of molding sands, Arch Foundry Eng., 8(2008) 119-122.

[19] P. Mrvar, M. Trbizan, J. Medved, Dilatation analysis of the eutectoid transformation of the ascast spheroidal graphite cast iron, Scand J Metall. 31(2002) 393-400. 